\title{
Engineering of Exciton Spatial Distribution in CdS Nanoplatelets
}

Yan Zhang, ${ }^{1 \dagger}$ Haibing Zhang, ${ }^{2 \dagger}$ Dongdong Chen, ${ }^{2}$ Cheng-Jun Sun, ${ }^{3}$ Yang Ren, ${ }^{3}$ Jianhui Jiang, ${ }^{1}$ Linjun Wang, ${ }^{2 *}$ Zheng $\mathrm{Li},{ }^{*}$ and Xiaogang Peng ${ }^{2 *}$

${ }^{1}$ State Key Laboratory of Chemo/Bio-Sensing and Chemometrics, College of Chemistry and Chemical Engineering, Hunan University, Changsha 410082, China

${ }^{2}$ Key Laboratory of Excited-State Materials of Zhejiang Province, Department of Chemistry, Zhejiang University, Hangzhou 310027, China

${ }^{3}$ X-ray Science Division, Advanced Photon Source Argonne National Laboratory, IL 60439, USA

†These authors contributed equally

*Corresponding author. Email: ljwang@zju.edu.cn, zli@hnu.edu.cn,xpeng@zju.edu.cn 


\section{Experimental Section \\ 1.1 Materials}

Cadmium acetate dihydrate ( $\geq 98 \%$ ), stearic acid (95\%), myristic acid ( $\geq 99 \%)$, sulfur powder (reagent grade, 100 mesh), cadmium sulfide powder (99.995\%, bulk), cadmium oxide, methyl stearate ( $\geq 99 \%)$, 1-octadecene (90\%, ODE), oleic acid (90\%), hexanoic acid ( $\geq 99 \%)$, 1-dodecanethiol ( $\geq 98 \%$, DDT), oleylamine (technical grade, 70\%) were purchased from Sigma-Aldrich. Hexyl mercaptan ( $>96 \%$, HXT) was purchased from TCI. Coumarin 500 was purchased from Exciton. Methanol (MeOH), chloroform, toluene, acetone, and acetonitrile were purchased from Sinopharm Reagents. All chemicals were used as received without any further purification.

\subsection{Synthesis of $\mathrm{CdS}$ nanocrystals}

\section{2-1 Preparation of $\mathrm{Cd}\left(\mathrm{C}_{2} \mathrm{H}_{3} \mathrm{O}_{2}\right)\left(\mathrm{C}_{18} \mathrm{H}_{33} \mathrm{O}_{2}\right)$}

Cadmium acetate dihydrate $(0.1066 \mathrm{~g}, 0.4 \mathrm{mmol})$, oleic acid $(0.113 \mathrm{~g}, 0.4 \mathrm{mmol})$ and $6.0 \mathrm{~g}$ ODE were bubbled with $\mathrm{Ar}$ for $10 \mathrm{mins}$, then heated to $160{ }^{\circ} \mathrm{C}$ under Ar flow and kept at $160{ }^{\circ} \mathrm{C}$ for additional 2 hours. And final products were cooled down to room temperature for further usage.

\section{2-2 Preparation of cadmium carboxylate $\left(\mathrm{Cd}(\mathrm{St})_{2}, \mathrm{Cd}(\mathrm{My})_{2}\right.$, and $\left.\mathrm{Cd}(\mathrm{Oa})_{2}\right)$}

Cadmium oxide and stearic acid/myristic acid/oleic acid ( 3 times the molar ratio of cadmium oxide) were first bubbled with Ar for 30 mins, then heated to $160{ }^{\circ} \mathrm{C}$ and kept at this temperature, until the color of the mixture evolved into almost transparent, after around 2 hours of reaction. During the cooling process, the solution was added into a large beaker with hot acetone, while kept under $55-60{ }^{\circ} \mathrm{C}$ and vigorous stirring for around $10-15$ mins. The white precipitates were separated from supernatant through timely vacuum filtration. And the purification procedure was repeated four more times, before putting the precipitates into a vacuum oven for overnight pumping treatments at room temperature. The final products were analyzed by infrared spectrum to assure the complete removal of excessive/free stearic acid/oleic acid added during the synthesis, before corresponding utilizations.

\section{2-3 Preparation of S precursor (S-ODE)}

The solution was prepared by dissolving $0.0320 \mathrm{~g}$ of sulfur $(1.0 \mathrm{mmol})$ in $20 \mathrm{~g}$ of ODE by gentle sonication and stored in a closed vial for further usage.

\section{2-4 Preparation of $\mathrm{Cd}_{3} \mathrm{~S}_{2}$ nanoplatelets}

Cadmium acetate dihydrate $(0.1066 \mathrm{~g}, 0.4 \mathrm{mmol})$, S-ODE (2.0032 g, $0.1 \mathrm{mmol} \mathrm{S})$, oleic acid $(0.113 \mathrm{~g}, 0.4$ mmol), oleylamine $(0.1 \mathrm{~g}, 0.38 \mathrm{mmol})$, and $5.9 \mathrm{~g}$ ODE were bubbled with Ar for $10 \mathrm{mins}$, then heated to 170 ${ }^{\circ} \mathrm{C}$ from room temperature in 10 mins and kept under Ar protection for another 5 mins.

\section{2-5 Preparation of $\mathrm{Cd}_{3} \mathrm{~S}_{4}$ nanoplatelets}

The purified and surface treated $\mathrm{Cd}_{3} \mathrm{~S}_{2}$ nanoplatelets were re-dispersed into $8 \mathrm{~mL}$ ODE, forming colloidal solution with the same optical density at the lowest energy exciton peak, compared with as-prepared Cd3S2 nanoplatelets, then, $0.1872 \mathrm{~g}$ DDT was added and heated to $65^{\circ} \mathrm{C}$, and maintained at $65^{\circ} \mathrm{C}$ for $8 \mathrm{~h}$.

\section{2-6 Preparation of $\mathrm{Cd}_{4} \mathrm{~S}_{3}$ nanoplatelets}

Cadmium acetate dihydrate $(0.1066 \mathrm{~g}, 0.4 \mathrm{mmol})$, S-ODE $(2.0032 \mathrm{~g}, 0.1 \mathrm{mmol} \mathrm{S})$, myristic acid $(0.0914 \mathrm{~g}$, $0.4 \mathrm{mmol}$ ), and $6.0 \mathrm{~g} \mathrm{ODE}$ were bubbled with $\mathrm{Ar}$ for $10 \mathrm{mins}$, then heated to $180^{\circ} \mathrm{C}$ from room temperature in 10 mins and kept under Ar flow for additional 30 mins.

\section{2-7 Preparation of $\mathrm{Cd}_{4} \mathrm{~S}_{5}$ nanoplatelets}

(a) Preparation of sulfur-terminated $\mathrm{Cd}_{4} \mathrm{~S}_{5}$ nanoplatelets with hydrocarbon chain as the ligands layer The purified $\mathrm{Cd}_{4} \mathrm{~S}_{3}$ nanoplatelets were re-dispersed into $8 \mathrm{~mL}$ ODE to form a colloidal solution with the same particle concentration of as-prepared $\mathrm{Cd}_{4} \mathrm{~S}_{3}$ nanoplatelets, then, $8 \mathrm{~mL}$ DDT was introduced and heated towards $65^{\circ} \mathrm{C}$ and kept at designated temperature for $8 \mathrm{~h}$.

(b) Preparation of sulfur-terminated $\mathrm{Cd}_{4} \mathrm{~S}_{5}$ nanoplatelets with alkylamine as the ligands layer

The purified $\mathrm{Cd}_{4} \mathrm{~S}_{3}$ nanoplatelets were re-dispersed into $4 \mathrm{~mL}$ ODE to form a colloidal solution with the same particle concentration of as-prepared $\mathrm{Cd}_{4} \mathrm{~S}_{3}$ nanoplatelets, then $\mathrm{H}_{2} \mathrm{~S}$ was introduced and heated towards $65^{\circ} \mathrm{C}$ and kept at designated temperature for $4 \mathrm{~h} . \mathrm{H}_{2} \mathrm{~S}$ was produced by reacting elemental $\mathrm{S}(0.32 \mathrm{~g}, 0.1 \mathrm{mmol})$ with oleylamine $(5.3498 \mathrm{~g}, 0.2 \mathrm{mmol})$ at $100^{\circ} \mathrm{C}$, which was directly carried into the reaction flask by Ar flow.

\section{2-8 Preparation of $\mathrm{Cd}_{5} \mathrm{~S}_{4}$ nanoplatelets}

Cadmium acetate dihydrate $(0.1066 \mathrm{~g}, 0.4 \mathrm{mmol})$, S-ODE (2.0032 g, $0.1 \mathrm{mmol} \mathrm{S})$, oleic acid $(0.113 \mathrm{~g}, 0.4$ $\mathrm{mmol}$ ), and $6.0 \mathrm{~g}$ ODE were bubbled with Ar for $10 \mathrm{mins}$, after switching to Ar protection, the solution was heated to $260{ }^{\circ} \mathrm{C}$ from room temperature in 15 mins, and maintained at $260{ }^{\circ} \mathrm{C}$ for $1 \mathrm{~min}$.

\section{2-9 Preparation of $\mathrm{Cd}_{5} \mathrm{~S}_{6}$ nanoplatelets}

The purified and surface treated $\mathrm{Cd}_{5} \mathrm{~S}_{4}$ nanoplatelets was re-dispersed in $8 \mathrm{~mL}$ ODE, with the formation of colloidal solution matching the particle concentration of as-prepared $\mathrm{Cd}_{5} \mathrm{~S}_{4}$ nanoplatelets, then, $0.1872 \mathrm{~g}$ DDT was added and heated to $65^{\circ} \mathrm{C}$ and kept at $65^{\circ} \mathrm{C}$ for $8 \mathrm{~h}$.

1.2-10 Preparation of $\mathrm{Cd}_{6} \mathrm{~S}_{\mathbf{5}}$ nanoplatelets

$\mathrm{Cd}(\mathrm{St})_{2}(0.1356 \mathrm{~g}, 0.2 \mathrm{mmol}), \mathrm{S}-\mathrm{ODE}(2.0032 \mathrm{~g}, 0.1 \mathrm{mmol} \mathrm{S})$, and $6.0 \mathrm{~g}$ ODE were bubbled with Ar for 10 mins, then heated to $190{ }^{\circ} \mathrm{C}$ from room temperature within 8 mins, and then kept at designated temperature 
under Ar flow for 8 mins, with the formation of CdS spheroidal nanocrystals possessing an UV-Vis absorption peak at $322 \mathrm{~nm}$. After cooling to room temperature, $0.1066 \mathrm{~g}$ cadmium acetate dihydrate $(0.4 \mathrm{mmol})$ was added, the solution was bubbled with Ar for 10 mins and then heated to $250{ }^{\circ} \mathrm{C}$ from room temperature in 15 mins, and kept at $250^{\circ} \mathrm{C}$ for additional $1 \mathrm{~min}$.

\section{2-11 Preparation of $\mathrm{Cd}_{6} \mathrm{~S}_{7}$ nanoplatelets}

The purified $\mathrm{Cd}_{6} \mathrm{~S}_{5}$ nanoplatelets were re-dispersed in $8 \mathrm{~mL}$ ODE, to form a colloidal solution with the same particle concentration of as-prepared $\mathrm{Cd}_{6} \mathrm{~S}_{5}$ nanoplatelets, and then $0.1872 \mathrm{~g}$ DDT was added and heated to 65 ${ }^{\circ} \mathrm{C}$ and kept at $65^{\circ} \mathrm{C}$ for $8 \mathrm{~h}$.

\section{2-12 Preparation of cadmium-terminated spheroidal CdS nanocrystals}

$\mathrm{Cd}(\mathrm{St})_{2}(0.0678 \mathrm{~g}, 0.1 \mathrm{mmol}), \mathrm{S}-\mathrm{ODE}(1.0016 \mathrm{~g}, 0.05 \mathrm{mmol} \mathrm{S})$, and $3.0 \mathrm{~g}$ ODE were bubbled with Ar for 10 mins, then heated to the designated temperature, and then kept at this temperature under Ar atmosphere, until the formation of $\mathrm{CdS}$ spheroidal nanocrystals with absorption peak at designated positions.

\section{2-13 Preparation of sulfur-terminated spheroidal CdS nanocrystals}

The purified CdS spheroidal nanocrystals were re-dispersed in $4 \mathrm{~mL}$ ODE, with the formation of colloidal solution matching the particle concentration of as-prepared CdS spheroidal nanocrystals, then, $0.0936 \mathrm{~g}$ DDT was added and heated to $65^{\circ} \mathrm{C}$ and kept at $65^{\circ} \mathrm{C}$ for $8 \mathrm{~h}$. During the preparation of this series of CdS spheroidal nanocrystals, small aliquots were taken out at different time intervals, diluted into chloroform/toluene, and recorded with corresponding UV-Vis spectra, to monitor the growth process.

\subsection{Purification and related treatments of $\mathrm{CdS}$ nanocrystals}

\section{3-1 Purification of CdS nanocrystals}

The CdS nanoplatelets were mixed with chloroform and oleylamine (10\% volume ratio of oleylamine), forming a clear solution. Then, a mixture of acetone and methanol (30\% volume ratio of methanol, and 5 times volume of the chloroform/oleylamine) was introduced, after sonication of $1 \mathrm{~min}$, the solution was centrifuged at $11000 \mathrm{rpm}$ for $5 \mathrm{mins}$. The supernatant was discarded, with precipitates collected for additional four rounds of aforementioned purification.

The purification of spheroidal CdS nanocrystals was the same as the CdS nanoplatelets, as mentioned above. 1.3-2 Surface treatments of CdS nanoplatelets

The purified CdS nanoplatelets were re-dispersed into $2 \mathrm{~mL}$ ODE with the same optical density as the sample before purification, $0.0482 \mathrm{~g} \mathrm{Cd}\left(\mathrm{C}_{2} \mathrm{H}_{3} \mathrm{O}_{2}\right)\left(\mathrm{C}_{18} \mathrm{H}_{33} \mathrm{O}_{2}\right)$ and $0.0141 \mathrm{~g}$ oleic acid were added, then bubbled with Ar for $10 \mathrm{mins}$, and heated to $120^{\circ} \mathrm{C}$ under Ar protection. The solution was kept at $120{ }^{\circ} \mathrm{C}$ for $5 \mathrm{~h}$, before cooling down to room temperature. Small aliquots were taken out at different time intervals, diluted into toluene, and recorded with corresponding UV-Vis spectra, to monitor the treatment process until UV-Vis absorption peak position blue-shift to the same position as the original sample.

The surface treated CdS nanoplatelets were added with equivalent volume of toluene and sonicated for 2 mins, then centrifuged at $4000 \mathrm{rpm}$ for $1 \mathrm{~min}$. The supernatant was discarded, with the precipitates dispersed in 2 $\mathrm{mL}$ toluene and sonicated for 2 mins, centrifuged at $4000 \mathrm{rpm}$ for another $1 \mathrm{~min}$. The supernatant was discarded, with precipitates collected for further usage. Control experiments were carried out in parallel to make sure that introduced $\mathrm{Cd}\left(\mathrm{C}_{2} \mathrm{H}_{3} \mathrm{O}_{2}\right)\left(\mathrm{C}_{18} \mathrm{H}_{33} \mathrm{O}_{2}\right)$ for surface treatments of $\mathrm{CdS}$ nanocrystals, would not interfere with the following experiments and characterizations.

\section{3-3 Quantification during purification}

We selected the asymmetric stretching $\left(1500-1575 \mathrm{~cm}^{-1}\right)$ from $\mathrm{Cd}(\mathrm{My})_{2}$ and the carbonyl vibration $(1743$ $\mathrm{cm}^{-1}$ ) from methyl stearate to measure a series of IR spectra with varied concentration ratios between Cd(My) and methyl stearate, and then quantified the corresponding absorbance values to fit an equation for the standard curve in Figure S6d. Then, methyl stearate was employed as the internal standard to quantify the amounts of $\mathrm{Cd}(\mathrm{My})_{2}$ after reaction and aforementioned purification process for the $\mathrm{Cd}_{4} \mathrm{~S}_{3}$ nanoplatelets, plotted as the red and blue curves in Figure S6c, respectively. Based on the average lateral dimension of $\mathrm{Cd}_{4} \mathrm{~S}_{3}$ nanoplatelets observed under TEM, a model was built to quantify the molar ratio between surface $\mathrm{Cd}$ atoms and the total amount of $\mathrm{S}$ atoms. Accordingly, the yield of $\mathrm{Cd}_{4} \mathrm{~S}_{3}$ nanoplatelets was calculated through the atomic model and quantified infrared spectrum. Then, the amount of cadmium carboxylate after purification was calculated from quantified infrared spectrum, and compared to the amount of $\mathrm{Cd}_{4} \mathrm{~S}_{3}$ nanoplatelets, resulting with a surface coverage of $100.6 \pm 0.09 \%$ for ligands on the NPL. This means that the experimental NPL samples are passivated completely.

\subsection{Instruments, characterizations, and calculations}

\section{4-1 Optical measurements}

\section{4-1.1 UV-Vis spectroscopy}

The UV-Vis spectra were recorded on Cary 8454 (Agilent) with a $1 \mathrm{~cm}$ optical pathlength quartz cell. At room temperature, the samples were diluted in proper solvent for measurement and corresponding comparisons.

\section{4-1.2 Photoluminescence spectroscopy}

Photoluminescence spectra were measured using a Cary Eclipse Fluorescence Spectrophotometer (Agilent) with a $1 \mathrm{~cm}$ optical pathlength quartz cell. The PLQY of CdS NPL was measured by comparing fluorescence 
intensity of coumarin 500 in methanol with CdS NPL in toluene, with the same absorbance value at excitation wavelength $(340 \mathrm{~nm})$ and similar fluorescence wavelength. The PLQY of $\mathrm{Cd}_{4} \mathrm{~S}_{3}$ and $\mathrm{Cd}_{4} \mathrm{~S}_{5} \mathrm{NPL}$ was calculated as $0.86 \%$ and close to zero, respectively. Since the $\mathrm{Cd}_{4} \mathrm{~S}_{5}$ NPL exhibited an absorption peak at $416 \mathrm{~nm}$, the PL intensities from $\mathrm{Cd}_{4} \mathrm{~S}_{5}$ NPL were indistinguishable for the wavelengths below and above $416 \mathrm{~nm}$, indicating that the signals detected in the PL measurements shall be considered mainly as noises.

1.4-2 Transmission electron microscopy (TEM) and scanning transmission electron microscopy (STEM) Transmission electron microscopy and high-resolution TEM (HRTEM) images were obtained with JEM2100Plus (JEOL), operated at $200 \mathrm{kV}$. The STEM measurements were carried out at a Titan ChemiSTEM/STwin electron microscope which operated at $200 \mathrm{kV}$. The purified samples were dissolved in toluene and directly dropped onto the copper grids coated with carbon film, and dried overtime in the hood.

1.4-3 Fourier transform infrared spectroscopy (FTIR)

FTIR were measured with Nicolet 870 FT-IR (Thermo) at room temperature. The instrument detector was chosen as mercury cadmium telluride narrowband detector (MCT/A), which was cooled down by liquid nitrogen, with a response range of $10000-650 \mathrm{~cm}^{-1}$. After the instrument was stable, multiple backgrounds from the air were acquired, and corresponding samples were analyzed on $\mathrm{KBr}$ plate.

\section{4-4 X-ray diffraction analysis (XRD)}

The experiments were carried out at 11-ID-C station of Advanced Photon Source at Argonne National Laboratory, with an X-ray wavelength of $0.1173 \AA$. The purified CdS nanoplatelets was re-dispersed into toluene, washed with $\mathrm{MeOH}$ for one more time, and the final precipitate was preserved and dried in a vacuum oven overnight before putting into a metal ring and sealed with Kapton tape for further analysis.

Some samples were also analyzed with Bruker D8 Advance operating at $40 \mathrm{kV} / 40 \mathrm{~mA}$, with a Cu Ka radiation source of $1.5418 \AA$. The purified CdS nanoplatelets were dried in a vacuum oven overnight and analyzed with samples on monocrystalline silicon substrate.

The simulation of the XRD patterns was conducted by running custom-code on Matlab. ${ }^{1}$ We build a layer-bylayer fashion along the thickness direction of nanoplatelets that have diverse layers capped with $\mathrm{Cd} / \mathrm{S}$ atoms. For the lateral directions, because the nanoplatelets could be easily rolled, the grain size employed in the simulations are also corrected. With optimized parameters, we can obtain simulated XRD patterns of CdS nanoplatelets. The lattice strain and the unit cell along the thickness and lateral directions can be readily acquired by comparing the calculated data and the standard value.

\section{4-5 Extended X-ray absorption fine structure (EXAFS)}

The EXAFS characterizations at the $\mathrm{Cd}-K$ edges were carried out at beamline 20-BM-B of Advance Photon Source at Argonne National Laboratory. Purified powder was sealed in a metal ring capped by the Kapton tape. A cadmium foil was put in the light-path, with spectra acquired simultaneously for X-ray energy calibration. The $\mathrm{Cd} K$-edge EXAFS data were processed by applying a standard method within the ATHENA software package. ${ }^{2}$ The normalized EXAFS were converted from energy to k-space and weighted, the data were then Fourier transformed to R-space without applying phase correction. Afterwards, the data was fitted with the ARTEMIS software package, to obtain the local environment around Cd atoms.

1.4-6 Energy-dispersive X-ray spectroscopy (EDX)

EDX was carried out under a Hitachi S-4800 scanning electron microscope equipped with a field emission gun and operated at $20 \mathrm{kV}$. The purified CdS nanoplatelets were re-dispersed into toluene, washed with $\mathrm{MeOH}$ for one more time, and the final precipitate was preserved and dried in a vacuum oven overnight before applying to the conducting tape for EDX analysis.

\section{4-7 Raman spectroscopy}

Raman spectra were collected using an inVia-reflex confocal Raman microscope. The $785 \mathrm{~nm}$ wavelength diode laser coupled to a holographic notch filter with a grafting of 1200 lines $\mathrm{mm}^{-1}$ was focused onto the sample, using a $50 \times$ objective and $100 \mathrm{~s}$ exposure time. One accumulation was collected per spot, with corresponding samples deposited on glass slides.

\section{4-8 Theoretical calculations}

We construct CdS slabs with exposed $\{100\}$ polar facets and consider formate and methyl as surface ligands for simplicity, respectively. All ab initio calculations are carried out within the Quantum Espresso package ${ }^{3}$ using the ultrasoft pseudopotential and the plane wave basis set with a kinetic energy cutoff of 60 Ry. The PBE exchange-correlation functional is adopted for structure optimizations and projected density of states (PDOS) calculations, while the HSE exchange-correlation functional is used for obtaining the direct bandgap energies. The Monkhorst-Pack mesh of $5 \times 5 \times 1,15 \times 15 \times 1$, and the Gamma point is utilized to sample the $\mathrm{k}$ points in the Brillouin zone for structure optimizations, PDOS, and bandgap calculations, respectively. Slab optimizations are completed until forces on all atoms are lower than $0.025 \mathrm{eV} / \AA$. 
Additional Figures

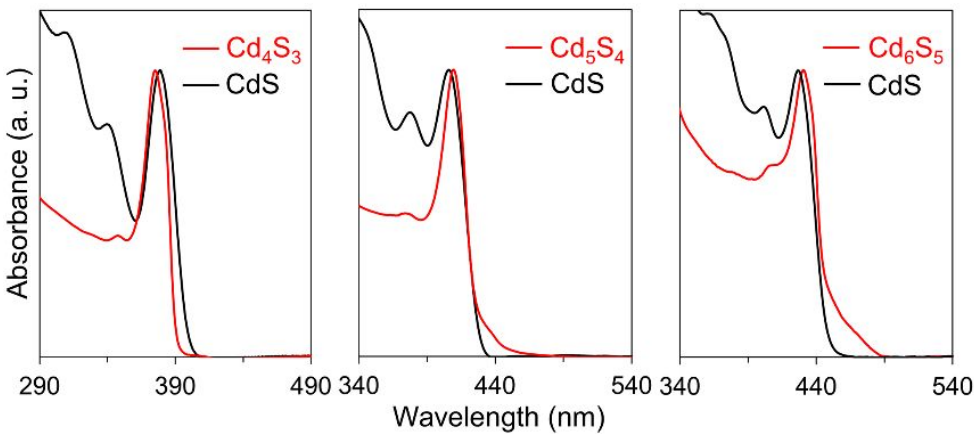

Figure S1. UV-Vis spectra of CdS nanoplatelets (red curves) and the corresponding spheroidal nanocrystals (black curves) with similar peak positions. 

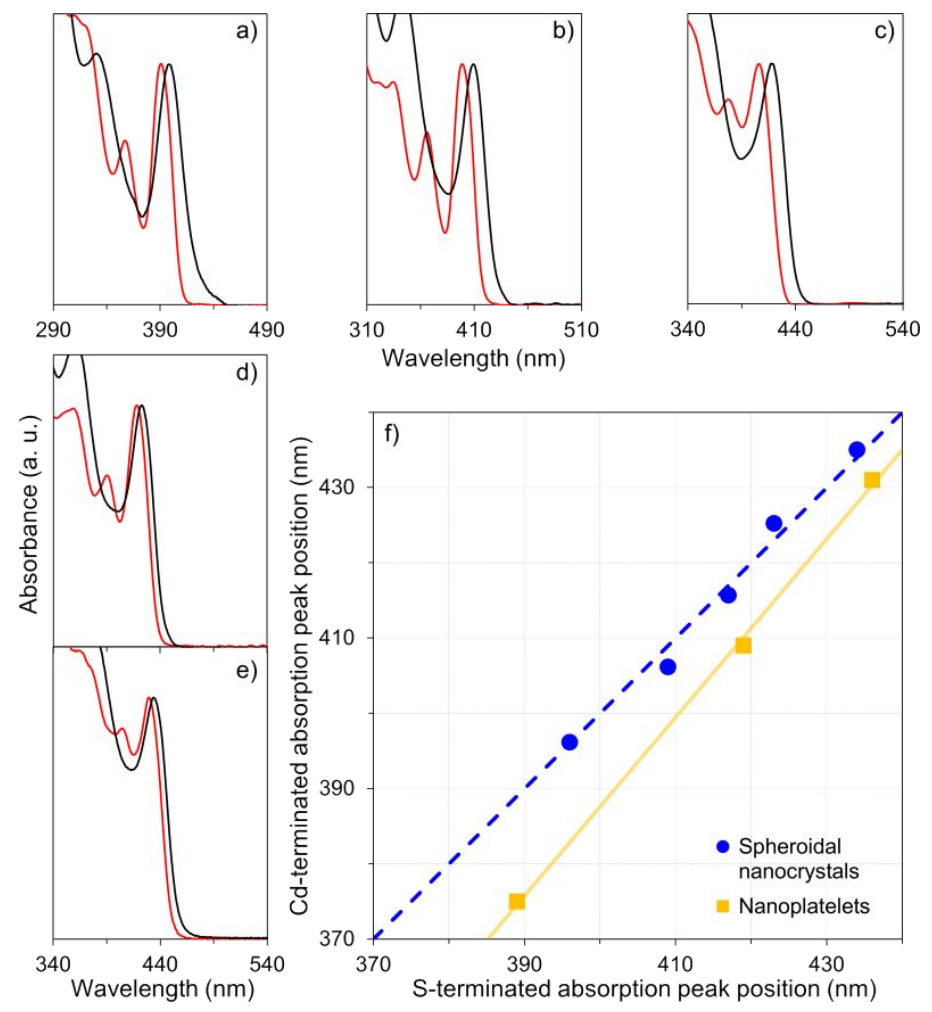

Figure S2. a)-e) UV-Vis spectra of five groups of Cd-terminated (red curves) and S-terminated (black curves) CdS spheroidal nanocrystals before/after the growth of an extra layer of sulfur atoms on the surfaces that are originally enclosed by cadmium atoms; f) comparison of absorption peak positions for similar sized CdS spheroidal nanocrystals terminated with either cadmium or sulfur atoms (blue spheroidal dots and dashed line), and same thickness of CdS nanoplatelets terminated with either cadmium or sulfur atoms (orange squares and solid line). As shown in the figures, the absorption peak positions of the original Cd-terminated CdS spheroidal nanocrystals have a distinct red shift a) from $389 \mathrm{~nm}$ to $396 \mathrm{~nm}$, b) from $399 \mathrm{~nm}$ to $409 \mathrm{~nm}$, c) from $409 \mathrm{~nm}$ to $417 \mathrm{~nm}, \mathrm{~d}$ ) from $419 \mathrm{~nm}$ to $423 \mathrm{~nm}$, and e) from $429 \mathrm{~nm}$ to $434 \mathrm{~nm}$, during epitaxial growth of a monolayer of sulfur, which are all quite small in comparison with the red-shift in Figure 1 for the nanoplatelets. In $\mathrm{f}$ ), the absorption peak positions for S-terminated CdS spheroidal nanocrystals are taken from the black curves in a)e), and for similar sized CdS spheroidal nanocrystals that are capped by Cd-terminated surfaces, the particle sizes from initial cadmium carboxylates capped CdS spheroidal nanocrystals are taken, together with the considerations of surface cadmium carboxylate layer, with corresponding transformation of cadmium carboxylates on the surface into cadmium sulfide, to estimate the size of Cd-terminated CdS spheroidal nanocrystals and corresponding absorption peak positions. ${ }^{4}$ For the $\mathrm{CdS}$ nanoplatelets, the $\mathrm{Cd} / \mathrm{S}$-terminated absorption peak positions with the same thickness are extracted from the absorption spectra of $\mathrm{Cd}_{4} \mathrm{~S}_{3}$ and $\mathrm{Cd}_{3} \mathrm{~S}_{4}$, $\mathrm{Cd}_{5} \mathrm{~S}_{4}$ and $\mathrm{Cd}_{4} \mathrm{~S}_{5}, \mathrm{Cd}_{6} \mathrm{~S}_{5}$ and $\mathrm{Cd}_{5} \mathrm{~S}_{6}$ in the main text. 


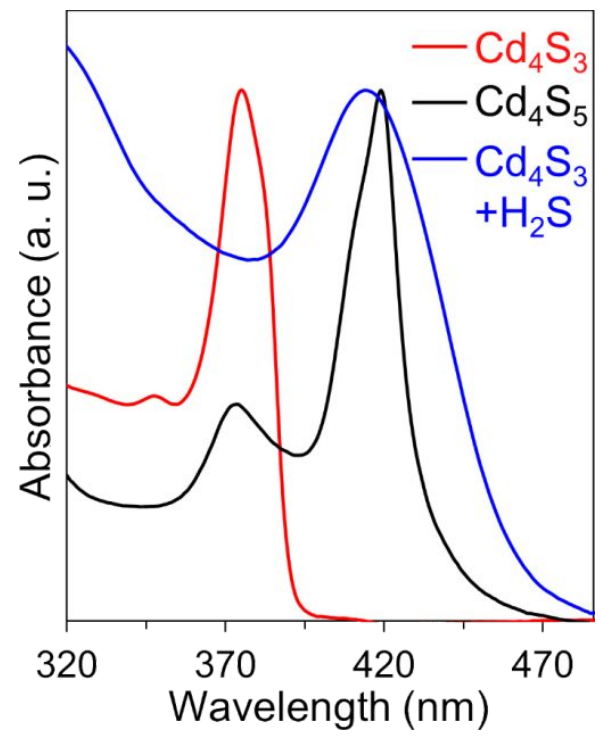

Figure S3. Comparison of the absorption spectra for Cd-terminated $\mathrm{Cd}_{4} \mathrm{~S}_{3}$ nanoplatelets with cadmium carboxylate as the surface layer (red curve) and S-terminated $\mathrm{Cd}_{4} \mathrm{~S}_{5}$ nanoplatelets with hydrocarbon chains (black curve) or alkylamine (blue curve) as the ligands layer.

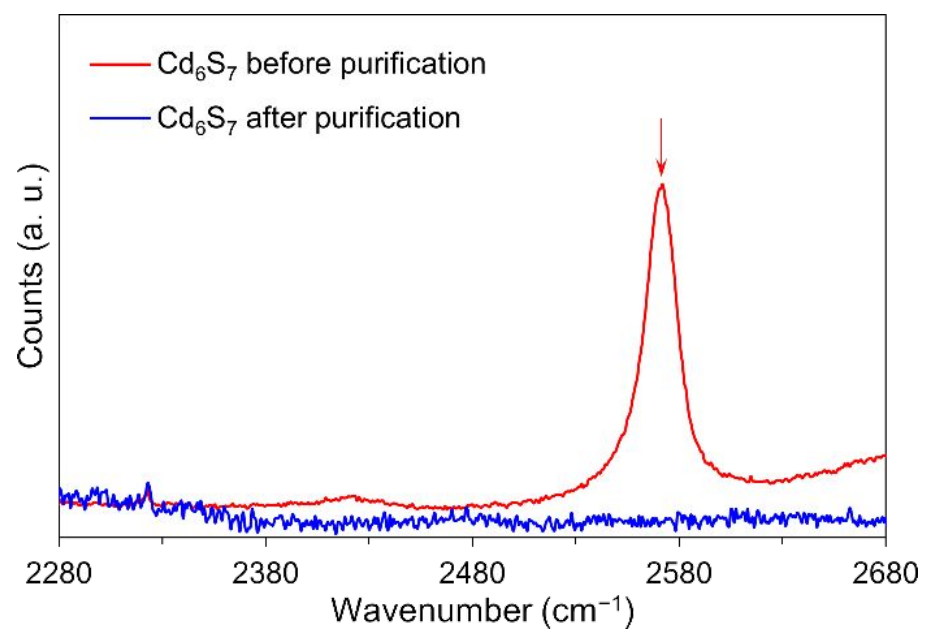

Figure S4. Raman spectra of $\mathrm{Cd}_{6} \mathrm{~S}_{7}$ nanoplatelets before (red curve) and after (blue curve) complete purification. The arrow marks the S-H stretch of DDT at $2572 \mathrm{~cm}^{-1}$. 


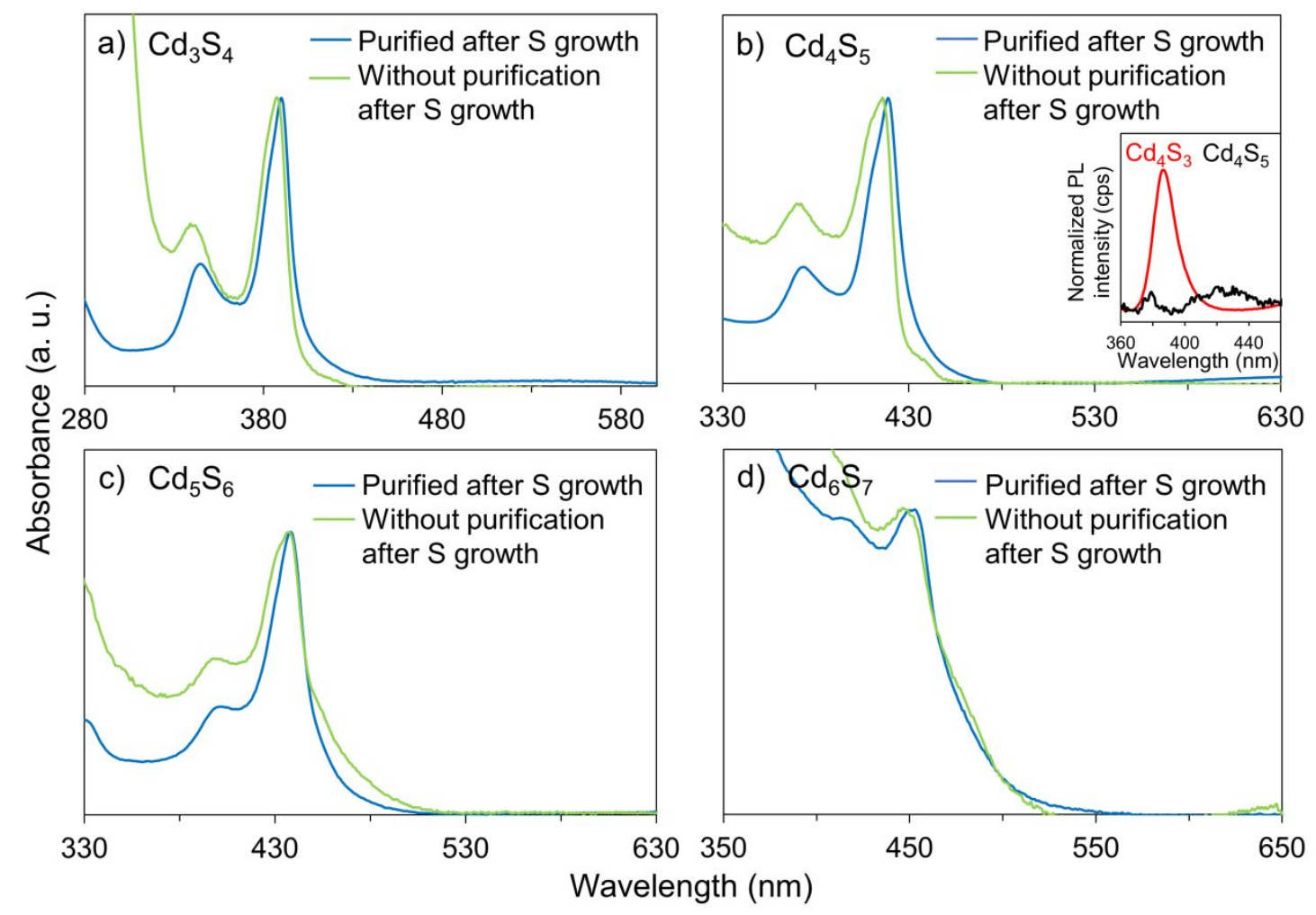

Figure S5. UV-Vis spectra of S-terminated $\mathrm{Cd}_{n} \mathrm{~S}_{m}$ nanoplatelets prepared from the original Cd-terminated $\mathrm{Cd}_{n} \mathrm{~S}_{m-2}$ ones with and without purification: a) $\mathrm{Cd}_{3} \mathrm{~S}_{4}$, b) $\mathrm{Cd}_{4} \mathrm{~S}_{5}$, c) $\mathrm{Cd}_{5} \mathrm{~S}_{6}$, and d) $\mathrm{Cd}_{6} \mathrm{~S}_{7}$. Inset within Figure $\mathrm{S} 5 \mathrm{~b}$ shows the PL spectra of the $\mathrm{Cd}_{4} \mathrm{~S}_{3}$ (red curve) and $\mathrm{Cd}_{4} \mathrm{~S}_{5}$ nanoplatelets (black curve). With optimized protocol of purification and surface treatments, the epitaxial growth of extra sulfur atoms on both basal planes reproducibly results in sharper excitonic peaks and lower absorption energies (blue curves), in comparison with those of the corresponding samples prepared without any purification/treatments (green curves). 

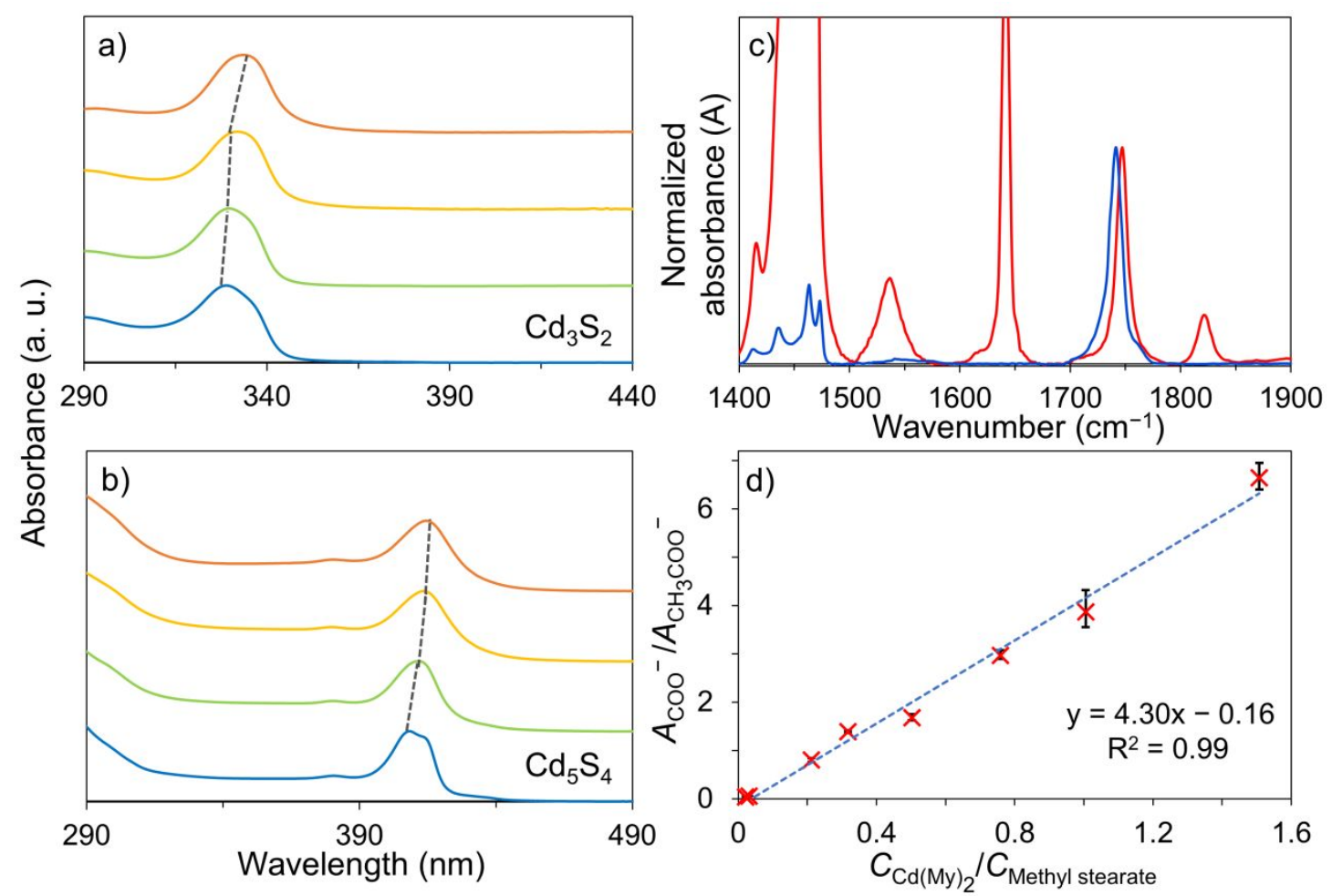

Figure S6. UV-Vis spectra of a) $\mathrm{Cd}_{3} \mathrm{~S}_{2}$ and b) $\mathrm{Cd}_{5} \mathrm{~S}_{4}$ nanoplatelets during the purification procedure. During the purification, the UV-Vis absorption peak was shifted a) from $329 \mathrm{~nm}$ to $334 \mathrm{~nm}$ for $\mathrm{Cd}_{3} \mathrm{~S}_{2}$ nanoplatelets and b) from $409 \mathrm{~nm}$ to $414 \mathrm{~nm}$ for $\mathrm{Cd}_{5} \mathrm{~S}_{4}$ nanoplatelets. c) IR spectra of $\mathrm{Cd}_{4} \mathrm{~S}_{3}$ nanoplatelets before (red curve) and after (blue curve) purification, the IR spectra were normalized with the vibrational signal $\left(1743 \mathrm{~cm}^{-1}\right)$ from internal standard of methyl stearate. d) Standard curve between the absorbance ratio and concentration ratio of $\mathrm{Cd}(\mathrm{My})_{2}$ and methyl stearate, quantified through IR measurements. 

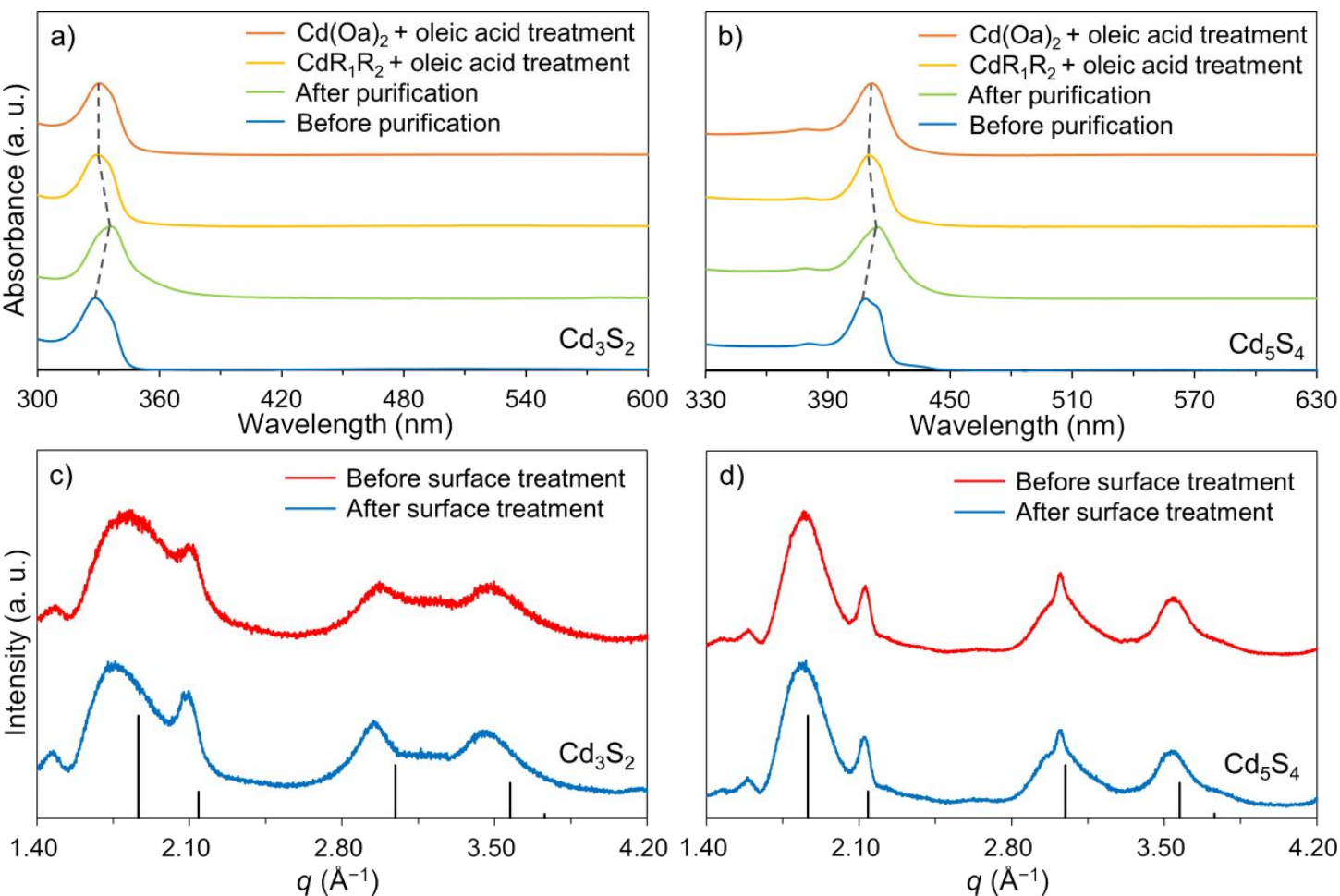

Figure S7. Two representative surface treatment methods (No.6 and No.9 in Table S2) for samples a) $\mathrm{Cd}_{3} \mathrm{~S}_{2}$ and b) $\mathrm{Cd}_{5} \mathrm{~S}_{4}$, and XRD patterns of CdS nanoplatelets before and after applying surface treatment protocol for samples c) $\mathrm{Cd}_{3} \mathrm{~S}_{2}$ and d) $\mathrm{Cd}_{5} \mathrm{~S}_{4}$. The sticks at the bottom of $\mathrm{C}$ and $\mathrm{D}$ correspond to the standard zinc-blende structure of CdS (ICSD No. 81925). The UV-Vis absorption peak of $\mathrm{Cd}_{3} \mathrm{~S}_{2}$ nanoplatelets was shifted from 329 $\mathrm{nm}$ to $334 \mathrm{~nm}$ during purification in a (blue line to green line), recovered to $329 \mathrm{~nm}$ while blue-shifted with either $\mathrm{Cd}\left(\mathrm{C}_{2} \mathrm{H}_{3} \mathrm{O}_{2}\right)\left(\mathrm{C}_{18} \mathrm{H}_{33} \mathrm{O}_{2}\right)+$ oleic acid (yellow curve) or $\mathrm{Cd}(\mathrm{Oa})_{2}+$ oleic acid (orange curve). The UV-Vis absorption peak of $\mathrm{Cd}_{5} \mathrm{~S}_{4}$ nanoplatelets was shifted from $409 \mathrm{~nm}$ to $414 \mathrm{~nm}$ during purification in b (blue curve to green curve), recovered to 409 when blue-shifted with either $\mathrm{Cd}\left(\mathrm{C}_{2} \mathrm{H}_{3} \mathrm{O}_{2}\right)\left(\mathrm{C}_{18} \mathrm{H}_{33} \mathrm{O}_{2}\right)+$ oleic acid (yellow curve) or $\mathrm{Cd}(\mathrm{Oa})_{2}+$ oleic acid (orange curve). $\mathrm{R}_{1}=\mathrm{C}_{2} \mathrm{H}_{3} \mathrm{O}_{2}{ }^{-}, \mathrm{R}_{2}=\mathrm{C}_{18} \mathrm{H}_{33} \mathrm{O}_{2}{ }^{-}$. 

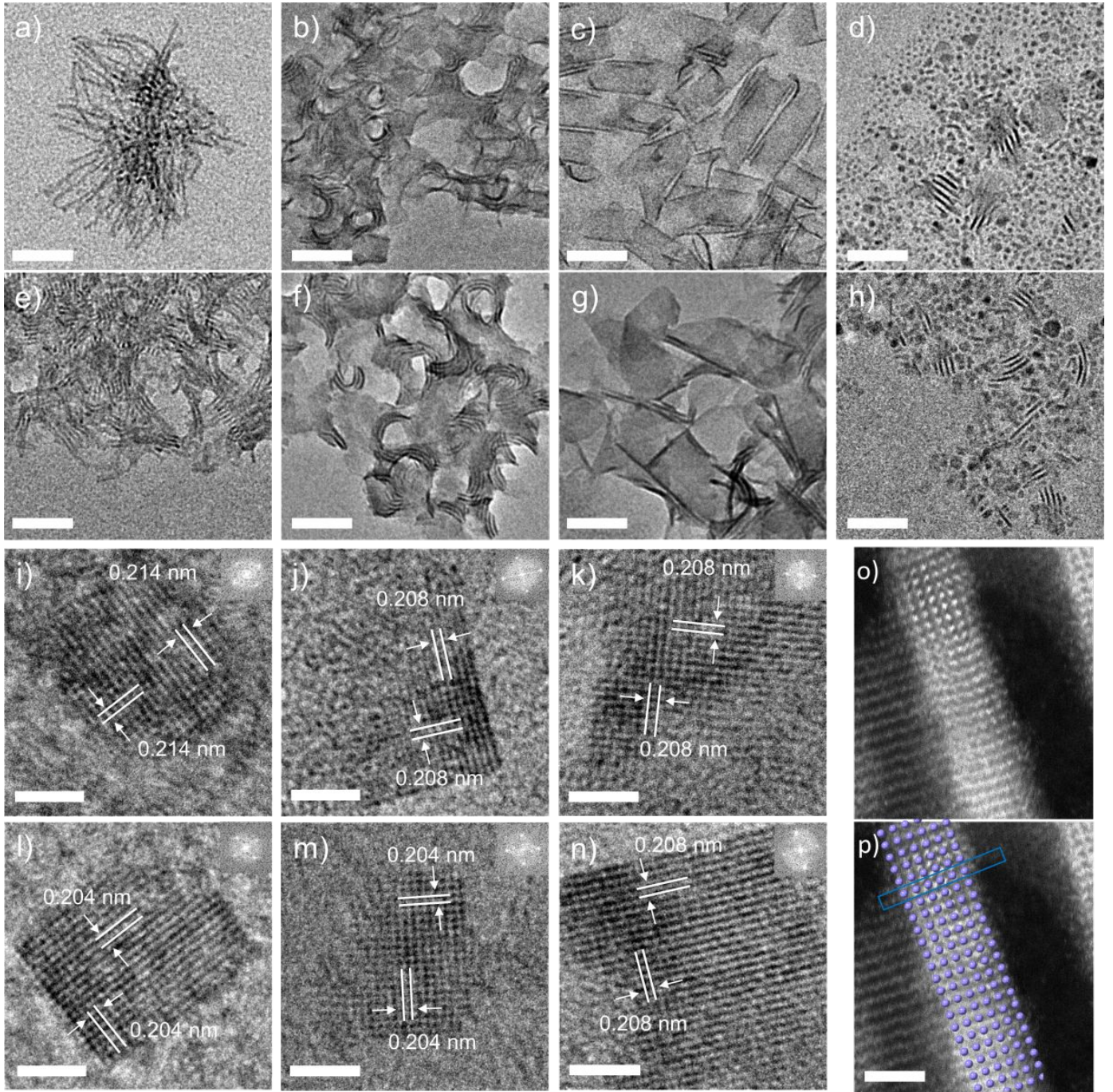

Figure S8. a)-h) TEM, i)-n) HRTEM, and o)-p) HR-STEM images of CdS nanoplatelets. a and i: $\mathrm{Cd}_{3} \mathrm{~S}_{2}$, b: $\mathrm{Cd}_{4} \mathrm{~S}_{3}$, c and j: $\mathrm{Cd}_{5} \mathrm{~S}_{4}, \mathrm{~d}$ and $\mathrm{k}: \mathrm{Cd}_{6} \mathrm{~S}_{5}$, e and $\mathrm{l}: \mathrm{Cd}_{3} \mathrm{~S}_{4}, \mathrm{f}: \mathrm{Cd}_{4} \mathrm{~S}_{5}, \mathrm{~g}$ and $\mathrm{m}: \mathrm{Cd}_{5} \mathrm{~S}_{6}$, h and $\mathrm{n}: \mathrm{Cd}_{6} \mathrm{~S}_{7}$. The distances between monolayers by fast Fourier transform are shown in the insets of i)-n). o) HR-STEM image of a $\mathrm{Cd}_{6} \mathrm{~S}_{7}$ nanoplatelet and $\mathrm{p}$ ) the same nanoplatelet with further superposition of atomic models. Since STEM is an atomic number $(Z)$ sensitive technique, the cadmium $(Z=48)$ atoms should exhibit brighter contrast than sulfur $(Z=16)$ atoms, the positions of bright dots in the STEM image are consistent with the locations of light violet balls (cadmium atoms), which were constructed from the standard CdS zinc-blende unit cell and with all the sulfur atoms removed. The scale bars are $50 \mathrm{~nm}$ in the TEM and $2 \mathrm{~nm}$ in the HRTEM/HR-STEM images. 


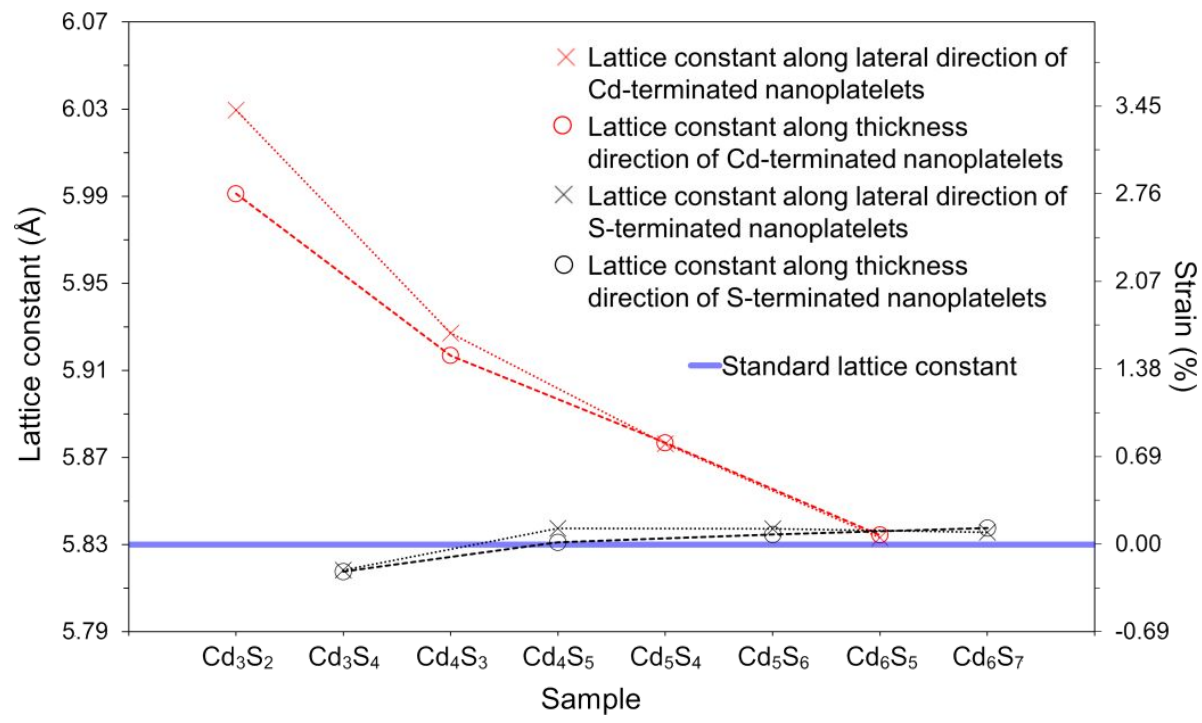

Figure S9. Lattice constant value and the corresponding strain along thickness and lateral directions for Cd/Sterminated CdS nanoplatelets. Lattice constant (left axis) and the corresponding strain (right axis) along thickness (circles) and lateral (crosses) directions for Cd-terminated (red markers) and S-terminated (black markers) CdS nanoplatelets, extracted from simulated XRD models, the black and red dotted lines are for guidance purposes. The standard value of lattice constant (5.83 $\AA$ ) from the zinc-blende structure of $\mathrm{CdS}$ (ICSD No. 81925) is also plotted as the blue solid line.

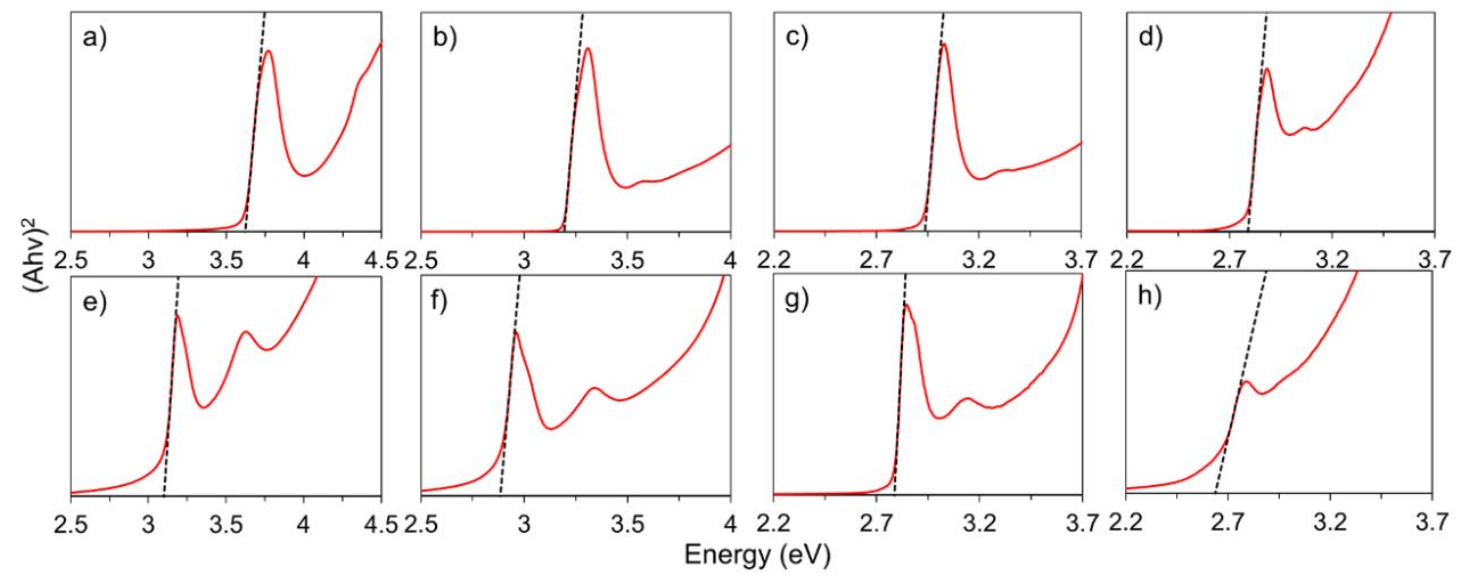

Figure S10. $(\mathrm{Ahv})^{2}$ as a function of the photon energy (in $\mathrm{eV}$ ) and the corresponding linear fitting (black dashed lines) for samples a) $\mathrm{Cd}_{3} \mathrm{~S}_{2}$, b) $\mathrm{Cd}_{4} \mathrm{~S}_{3}$, c) $\mathrm{Cd}_{5} \mathrm{~S}_{4}$, d) $\mathrm{Cd}_{6} \mathrm{~S}_{5}$, e) $\left.\mathrm{Cd}_{3} \mathrm{~S}_{4}, \mathrm{f}\right) \mathrm{Cd}_{4} \mathrm{~S}_{5}$, g) $\mathrm{Cd}_{5} \mathrm{~S}_{6}$, and h) $\mathrm{Cd}_{6} \mathrm{~S}_{7}$. 


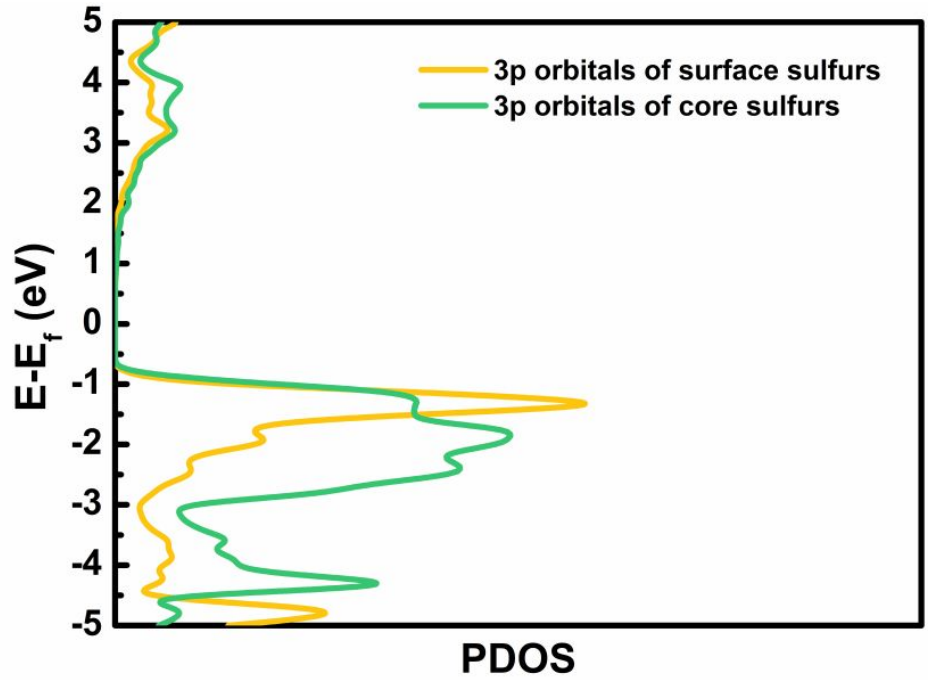

Figure S11. Projected density of states associated with the $3 p$ orbitals of surface and core sulfurs for $\mathrm{Cd}_{4} \mathrm{~S}_{5}$. $\mathrm{E}_{\mathrm{f}}$ is the Fermi energy. 


\section{Additional Tables}

Table S1. Features of the lowest energy absorption peaks in CdS nanoplatelets. $\lambda_{\max }$ is the wavelength of the lowest energy absorption peak. HWHM is the half width at half maximum along the lower energy side of the corresponding absorption peak. $\Delta \lambda_{\max }$ and $\Delta \mathrm{E}$ correspond to the shift of peak positions at the lowest energy absorption, in the scale of wavelength and energy, respectively, while transforming from Cd-terminated to Sterminated $\mathrm{CdS}$ nanoplatelets.

\begin{tabular}{|c|c|c|c|c|c|}
\hline Sample & $\begin{array}{l}\lambda_{\max } \\
(\mathrm{nm})\end{array}$ & $\begin{array}{c}\text { HWHM } \\
\text { (nm) }\end{array}$ & $\begin{array}{c}\text { HWHM } \\
(\mathrm{meV})\end{array}$ & $\begin{array}{l}\Delta \lambda_{\max } \\
\text { (nm) }\end{array}$ & $\begin{array}{c}\Delta \mathrm{E} \\
(\mathrm{meV})\end{array}$ \\
\hline $\mathrm{Cd}_{3} \mathrm{~S}_{2}$ & 329 & 10.5 & 117 & & \\
\hline $\mathrm{Cd}_{3} \mathrm{~S}_{4}$ & 389 & 12 & 95 & 60 & 581 \\
\hline $\mathrm{Cd}_{4} \mathrm{~S}_{3}$ & 375 & 11 & 94 & & \\
\hline $\mathrm{Cd}_{4} \mathrm{~S}_{5}$ & 419 & 12 & 82 & 44 & 347 \\
\hline $\mathrm{Cd}_{5} \mathrm{~S}_{4}$ & 409 & 10 & 72 & & \\
\hline $\mathrm{Cd}_{5} \mathrm{~S}_{6}$ & 436 & 8 & 51 & 27 & 188 \\
\hline $\mathrm{Cd}_{6} \mathrm{~S}_{5}$ & 430 & 12 & 78 & & \\
\hline $\mathrm{Cd}_{6} \mathrm{~S}_{7}$ & 445 & 38 & 219 & 15 & 97 \\
\hline
\end{tabular}


Table S2. Optimization of the surface treatment procedure for the CdS nanoplatelets after purification. With the trials of addition of various cadmium carboxylates/ligands to restore the original absorption features of CdS nanoplatelets. $\mathrm{R}_{1}=\mathrm{C}_{2} \mathrm{H}_{3} \mathrm{O}_{2}^{-}, \mathrm{R}_{2}=\mathrm{C}_{18} \mathrm{H}_{33} \mathrm{O}_{2}^{-}$.

\begin{tabular}{cccccc}
\hline Protocol & Solvent & Additive & $\mathrm{T}\left({ }^{\circ} \mathrm{C}\right)$ & Time $(\mathrm{h})$ & Peak $(\mathrm{nm})$ \\
\hline 1 & ODE & Cd(Ac $)_{2}$ & 160 & 17 & 413 \\
2 & ODE & Cd(Ac) $)_{2}$ & 200 & 17 & 418 \\
3 & ODE & oleic acid & 120 & 10 & 422 \\
4 & ODE & Cd(Ac) $)_{2}+$ oleic acid & 120 & 50 & 409 \\
5 & ODE & Cd(Oa $)_{2}$ & 120 & 14 & 413 \\
6 & ODE & $\mathrm{Cd}(\mathrm{Oa})_{2}+$ oleic acid & 120 & 10 & 409 \\
7 & Toluene & Cd(Ac) $)_{2}$ & 120 & 16 & 414 \\
8 & Toluene & oleic acid & 120 & 16 & 414 \\
9 & ODE & $\mathrm{CdR}_{1} \mathrm{R}_{2}+$ oleic acid & 120 & 5 & 409 \\
\hline
\end{tabular}


Table S3. Molar ratio between Cd and S from EDX of CdS nanoplatelets, together with the corresponding theoretical values.

\begin{tabular}{ccc}
\hline Sample & $\begin{array}{c}\mathrm{Cd}: \mathrm{S} \\
\text { (experimental) }\end{array}$ & $\begin{array}{c}\mathrm{Cd}: \mathrm{S} \\
\text { (theoretical) }\end{array}$ \\
\hline $\mathrm{Cd}_{3} \mathrm{~S}_{2}$ & $1.51 \pm 0.024$ & 1.5 \\
$\mathrm{Cd}_{3} \mathrm{~S}_{4}$ & $0.75 \pm 0.066$ & 0.75 \\
$\mathrm{Cd}_{4} \mathrm{~S}_{3}$ & $1.32 \pm 0.087$ & 1.33 \\
$\mathrm{Cd}_{4} \mathrm{~S}_{5}$ & $0.75 \pm 0.033$ & 0.8 \\
$\mathrm{Cd}_{5} \mathrm{~S}_{4}$ & $1.25 \pm 0.023$ & 1.25 \\
$\mathrm{Cd}_{5} \mathrm{~S}_{6}$ & $0.87 \pm 0.041$ & 0.83 \\
$\mathrm{Cd}_{6} \mathrm{~S}_{5}$ & $1.25 \pm 0.049$ & 1.2 \\
$\mathrm{Cd}_{6} \mathrm{~S}_{7}$ & $0.78 \pm 0.0086$ & 0.86 \\
$\mathrm{CdS}($ bulk & 1 & 1 \\
\hline
\end{tabular}


Table S4. Lattice constant and the corresponding strain along thickness and lateral directions for $\mathrm{Cd} / \mathrm{S}$ terminated CdS nanoplatelets. Lattice constant and the corresponding strain along thickness and lateral directions for CdS nanoplatelets, extracted from simulated XRD models. The standard value of the lattice constant $(5.83 \AA)$ from the zinc-blende structure of CdS (ICSD No. 81925) is taken to calculate the corresponding strain values. The significant figures of lattice constants and strain values are rounded to decimal places, with a precision of 2 .

\begin{tabular}{|c|c|c|c|c|}
\hline Sample & $\begin{array}{l}\text { Lattice constant along } \\
\text { the lateral direction } \\
(\AA)\end{array}$ & $\begin{array}{l}\text { Lateral strain } \\
(\%)\end{array}$ & $\begin{array}{l}\text { Lattice constant along } \\
\text { the thickness direction } \\
(\AA)\end{array}$ & $\begin{array}{c}\text { Thickness strain } \\
(\%)\end{array}$ \\
\hline $\mathrm{Cd}_{3} \mathrm{~S}_{2}$ & $6.03 \pm 0.15$ & 3.41 & $5.99 \pm 0.19$ & 2.76 \\
\hline $\mathrm{Cd}_{3} \mathrm{~S}_{4}$ & $5.82 \pm 0.15$ & -0.21 & $5.82 \pm 0.15$ & -0.22 \\
\hline $\mathrm{Cd}_{4} \mathrm{~S}_{3}$ & $5.93 \pm 0.16$ & 1.66 & $5.92 \pm 0.16$ & 1.48 \\
\hline $\mathrm{Cd}_{4} \mathrm{~S}_{5}$ & $5.84 \pm 0.14$ & 0.12 & $5.83 \pm 0.14$ & 0.01 \\
\hline $\mathrm{Cd}_{5} \mathrm{~S}_{4}$ & $5.88 \pm 0.15$ & 0.79 & $5.88 \pm 0.15$ & 0.79 \\
\hline $\mathrm{Cd}_{5} \mathrm{~S}_{6}$ & $5.84 \pm 0.14$ & 0.12 & $5.83 \pm 0.14$ & 0.07 \\
\hline $\mathrm{Cd}_{6} \mathrm{~S}_{5}$ & $5.83 \pm 0.14$ & 0.05 & $5.83 \pm 0.14$ & 0.07 \\
\hline $\mathrm{Cd}_{6} \mathrm{~S}_{7}$ & $5.84 \pm 0.14$ & 0.09 & $5.84 \pm 0.14$ & 0.12 \\
\hline
\end{tabular}


Table S5. Bandgap energy $\left(E_{g}\right)$ of CdS nanoplatelets extracted from the X-intercept from Figure S10.

\begin{tabular}{cc}
\hline Sample & $\mathrm{E}_{\mathrm{g}}(\mathrm{eV})$ \\
\hline $\mathrm{Cd}_{3} \mathrm{~S}_{2}$ & 3.62 \\
$\mathrm{Cd}_{3} \mathrm{~S}_{4}$ & 3.10 \\
$\mathrm{Cd}_{4} \mathrm{~S}_{3}$ & 3.19 \\
$\mathrm{Cd}_{4} \mathrm{~S}_{5}$ & 2.88 \\
$\mathrm{Cd}_{5} \mathrm{~S}_{4}$ & 2.94 \\
$\mathrm{Cd}_{5} \mathrm{~S}_{6}$ & 2.79 \\
$\mathrm{Cd}_{6} \mathrm{~S}_{5}$ & 2.79 \\
$\mathrm{Cd}_{6} \mathrm{~S}_{7}$ & 2.64 \\
\hline
\end{tabular}




\section{References}

(1) Chen, D.; Gao, Y.; Chen, Y.; Ren, Y.. Peng, X. Structure identification of two-dimensional colloidal semiconductor nanocrystals with atomic flat basal planes. Nano Lett. 2015, 15 (7), 4477-4482.

(2) Ravel, B.. Newville, M. ATHENA, ARTEMIS, HEPHAESTUS: Data analysis for X-ray absorption spectroscopy using IFEFFIT. J. Synchrotron Radiat. 2005, 12 (Pt 4), 537-41.

(3) Giannozzi, P.; Andreussi, O.; Brumme, T.; Bunau, O.; Buongiorno Nardelli, M.; Calandra, M.; Car, R.; Cavazzoni, C.; Ceresoli, D.; Cococcioni, M.; Colonna, N.; Carnimeo, I.; Dal Corso, A.; de Gironcoli, S.; Delugas, P.; DiStasio, R. A.; Ferretti, A.; Floris, A.; Fratesi, G.; Fugallo, G.; Gebauer, R.; Gerstmann, U.; Giustino, F.; Gorni, T.; Jia, J.; Kawamura, M.; Ko, H. Y.; Kokalj, A.; Kucukbenli, E.; Lazzeri, M.; Marsili, M.; Marzari, N.; Mauri, F.; Nguyen, N. L.; Nguyen, H. V.; Otero-de-la-Roza, A.; Paulatto, L.; Ponce, S.; Rocca, D.; Sabatini, R.; Santra, B.; Schlipf, M.; Seitsonen, A. P.; Smogunov, A.; Timrov, I.; Thonhauser, T.; Umari, P.; Vast, N.; Wu, X.. Baroni, S. Advanced capabilities for materials modelling with quantum espresso. J. Phys.: Condens. Matter 2017, 29 (46), 465901-465931.

(4) Li, J.; Chen, J.; Shen, Y.. Peng, X. Extinction coefficient per CdE (E = Se or S) unit for zinc-blende CdE nanocrystals. Nano Res. 2018, 11 (8), 3991-4004. 